\section{STATMAT}

(Jurnal Statistika dan Matematika)

\title{
Sistem Pendukung Keputusan Dalam Pemilihan Perusahaan Jasa Pengiriman Terbaik Dengan Menggunakan Metode AHP dan TOPSIS
}

\author{
Ilmadi $^{1, \text { a) }}$, Mita Suryani ${ }^{2, \text { b) }}$ \\ ${ }^{1}$ Program Studi Matematika Fakultas Matematika dan Ilmu Pengetahuan Alam Universitas Pamulang \\ ${ }^{2}$ Program Studi Matematika Fakultas Matematika dan Ilmu Pengetahuan Alam Universitas Pamulang \\ Email: ${ }^{\text {a) }}$ 1..ilmadi@yahoo.com, ${ }^{\text {b) }}$ namitha715@gmail.com
}

\begin{abstract}
This research was conducted with the background of the desire to know the best shipping service company. One way is to calculate using a combination of AHP and TOPSIS methods. The data used are primary data from the results of questionnaires of shipping service users, namely online sellers, online buyers and the general public. The results showed that the selection of shipping services based on consumer preferences was influenced by shipping costs with priority weights of 0.1884 , delivery time 0.1838 , shipment security 0.1689 , area coverage 0.1504 , service options 0.1094 , online tracking 0,1008 and compensation of 0.9830 . The best shipping service company is JNE with JNE value with a value of 0.6531, TIKI of 0.6136 , and Pos Indonesia of 0.3969 . So that JNE is the best shipping service company.
\end{abstract}

keywords : Shipping service companies, criteria, AHP, TOPSIS

\begin{abstract}
Abstrak
Penelitian ini dilakukan dengan dilatarbelakangi oleh keinginan untuk mengetahui perusahaan jasa pengiriman terbaik. Salah satu caranya adalah dengan perhitungan menggunakan kombinasi metode AHP dan TOPSIS. Data yang digunakan adalah data primer dari hasil kuisioner pengguna jasa pengiriman yakni penjual online, pembeli online dan masyarakat umum. Hasil penelitian menunjukkan pemilihan perusahaan jasa pengiriman berdasarkan preferensi konsumen dipengaruhi oleh biaya kirim dengan bobot prioritas sebesar 0,1884, waktu pengiriman 0,1838, keamanan kiriman 0,1689, jangkauan area 0,1504, pilihan layanan 0,1094 , pelacakan online 0,1008 dan ganti rugi 0,9830 . Perusahaan jasa pengiriman terbaik adalah JNE dengan nilai JNE dengan nilai sebesar 0,6531, TIKI sebesar 0,6136, dan Pos Indonesia sebesar 0,3969. Sedemikian sehingga JNE merupakan perusahaan jasa pengiriman yang terbaik.
\end{abstract}

kata kunci :Perusahaan jasa pengiriman, kriteria, AHP, TOPSIS

\section{PENDAHULUAN}

\subsection{Latar Belakang Masalah}

Di dalam era globalisasi dan kemajuan teknologi sekarang ini, perusahaan jasa pengiriman sangat dibutuhkan keberadannya. Sebagai contoh, dengan semakin berkembangnya teknologi yang mendukung kegiatan usaha perdagangan secara online, banyak pelaku usaha perdangangan yang memanfaatkan hal tersebut untuk memperoleh pangsa pasar yang lebih luas demi mendapatkan keuntungan yang lebih tinggi.

Dalam proses perdagangan secara online tersebut, tentunya peran dari perusahaan jasa pengiriman sangat dibutuhkan demi lancarnya usaha yang dijalankan. Namun para pelaku usaha dihadapkan pada suatu keadaan dimana orang tersebut harus memutuskan untuk memilih satu dari beberapa pilihan perusahaan jasa pengiriman yang ada. 


\section{STATMAT}

(Jurnal Statistika dan Matematika)
P-ISSN: 2655-3724

STATMAT (Jurnal Statistika dan Matematika), Vol. 1, No. 1, Januari 2019 Halaman : 78-87

@ Prodi S-1 Matematika FMIPA Unpam

Seiring dengan kemajuan teknologi, sekarang ini pelaku usaha perdagangan online juga tidak hanya bisa menawarkan produk melalui media sosial seperti Facebook, What's App, BBM dan Instagram. Namun mereka kini dimudahkan dengan adanya marketplace seperti Bukalapak, Lazada, Shopee dan lain-lain. Berbeda dengan transaksi jual beli melalui media sosial yang biasanya pengirim atau pihak penjual yang menentukan pemilihan perusahaan jasa pengiriman, dalam transaksi jual beli di marketplace ini keputusan pemilihan perusahaan jasa pengiriman berada di tangan pembeli.

Selain para pelaku usaha perdagangan online, pembeli online baik dari media sosial ataupun konsumen marketplace, masyarakat umum yang tidak melakukan usaha perdagangan online pun membutuhkan peran dari perusahaan jasa pengiriman, seperti untuk mengirimkan makanan, pakaian, dokumen dan lain sebagainya dengan alasan efisiensi waktu dan biaya.

Di Indonesia, dengan semakin majunya usaha perdangangan online serta minat masyarakat umum untuk menggunakan jasa pengiriman daripada mengantarkan sendiri ke tujuan, maka hal tersebut berdampak positif pada omset perusahaan jasa pengiriman, sehingga banyak perusahaan jasa pengiriman yang bersaing untuk dapat menjadi pilihan perusahaan penyedia jasa pengiriman yang terbaik bagi pedagang online, pembeli online dan masyarakat umum.

Kepuasan yang diberikan oleh perusahaan kepada pelanggan merupakan salah satu faktor yang menentukan daya saing untuk memenangkan persaingan. Jika pelanggan tidak puas, maka mereka akan menyikapi dengan meninggalkan perusahaan dan beralih menjadi pelanggan pihak pesaing, hal ini tentu akan menurunkan keuntungan dan pada akhirnya akan menyebabkan kerugian bagi perusahaan jasa pengiriman.

Persaingan yang ketat mendorong perusahaan-perusahaan jasa pengiriman untuk dapat mempertahankan pasarnya sehingga tetap dipilih dan dapat meningkatkan jumlah pelanggan. Persaingan sering kali terjadi dalam hal biaya kirim, sistem tracking atau pelacakan, penggantian rugi, waktu pengiriman, jangkauan area, pilihan layanan dan tentunya keamanan dari kiriman. Alternatif yang digunakan dalam penelitian ini adalah perusahaan jasa pengiriman berupa Pos Indonesia, TIKI dan JNE, dengan dasar ketiga perusahaan ini adalah perusahaan jasa pengiriman yang telah cukup lama berdiri dibandingkan dengan perusahaan-perusahaan jasa pengiriman lainnya di Indonesia khususnya di Tangerang Selatan dengan jumlah konsumen atau pelanggan yang cukup banyak.

Metode yang dapat digunakan untuk mengatasi masalah pemilihan alternatif terbaik adalah MultiCriteria Decision Making (MCDM). Metode MCDM ini terdiri dari beberapa jenis metode seperti Weight Sum Model (WSM), SMART, Simple Additive Weighting (SAW), Weight Product (WP), Technique For Order Preference by Similarity to Ideal Solution (TOPSIS), Profile Matching, Analytical Hierarchy Process (AHP) dan lain sebagainya. Dari masing-masing metode tersebut tentunya memiliki karakteristik dan kriteria penggunaan yang berbeda. 
(Jurnal Statistika dan Matematika)
P-ISSN: 2655-3724

STATMAT (Jurnal Statistika dan Matematika), Vol. 1, No. 1, Januari 2019 Halaman : 78-87

@Prodi S-1 Matematika FMIPA Unpam

Metode Analytical Hierarchy Process (AHP) yang dikembangkan oleh Thomas Saaty merupakan metode untuk membuat urutan alternative keputusan dan memilih yang terbaik pada saat pengambilan keputusan yang memiliki beberapa tujuan atau kriteria untuk mengambil keputusan tertentu. Peralatan metode AHP adalah hirarki fungsional dengan input utamanya persepsi manusia. (Sari, 2017:127).

Metode AHP merupakan teknik pengambilan keputusan/optimasi multivariate yang digunakan dalam analisis kebijaksanaan. Pada hakekatnya AHP merupakan suatu model pengambil keputusan yang komprehensif dengan memperhitungkan hal-hal yang bersifat kualitatif dan kuatitatif (Pratiwi, 2017:27). Sementara TOPSIS adalah salah satu metode pengambilan keputusan multikriteria yang pertama kali diperkenalkan oleh Yoon dan Hwang (1981).

Metode yang akan digunakan dalam penelitian ini sebagai pendukung sistem keputusan dalam pemilihan perusahaan jasa pengiriman terbaik adalah metode Analytical Hierarchy Process (AHP) dan metode Technique For Order Preference by Similarity to Ideal Solution (TOPSIS), karena metode AHP adalah metode terbaik dalam perhitungan bobot baik bobot kriteria ataupun alternatif dengan memperhatikan konsistensi penilaian. Sedangkan metode TOPSIS digunakan oleh peneliti untuk melakukan perangkingan alternatif terbaik dimana perangkingan juga memperhatikan konsep bahwa alternatif yang terbaik tidak hanya memiliki jarak terpendek dari solusi ideal positif, tetapi juga memilik jarak terpanjang dari solusi ideal negatif.

\subsection{Rumusan Masalah}

Berdasarkan latar belakang yang telah dikemukakan, beberapa rumusan permasalahan yang ditemui antara lain adalah:

1.2.1. Bagaimana preferensi konsumen mengenai bobot prioritas kriteria dan alternatif pada setiap kriteria dalam pemilihan perusahaan jasa pengiriman dengan menggunakan metode AHP ?

1.2.2. Bagaimana preferensi konsumen dalam pemilihan perusahaan jasa pengiriman terbaik dengan menggunakan metode TOPSIS?

\subsection{Tujuan Penelitian}

Adapun tujuan penelitian yang dilakukan adalah:

1.3.1. Mengetahui preferensi konsumen mengenai bobot prioritas kriteria dan alternatif pada setiap kriteria dalam pemilihan perusahaan jasa pengiriman dengan menggunakan metode AHP.

1.3.2. Mengetahui preferensi konsumen dalam pemilihan perusahaan jasa pengiriman terbaik dengan menggunakan metode TOPSIS 
(Jurnal Statistika dan Matematika)
P-ISSN: 2655-3724

STATMAT (Jurnal Statistika dan Matematika), Vol. 1, No. 1, Januari 2019 Halaman : 78-87

@Prodi S-1 Matematika FMIPA Unpam

\subsection{Manfaat Penelitian}

Adapun manfaat dari penelitian yang dilakukan adalah:

1.4.1. Sebagai salah satu alternatif untuk membantu masyarakat diantaranya pelaku usaha perdagangan online, pembeli online dan masyarakat umum dalam pemilihan perusahaan jasa pengiriman yang sesuai dengan keinginan.

1.4.2. Sebagai bahan acuan bagi penelitian sejenis terutama pengetahuan mengenai Sistem Pendukung Keputusan (SPK).

\section{METODE PENELITIAN}

\subsection{Waktu dan Tempat Penelitian}

Penelitian ini dilaksanan di Kota Tangerang Selatan, Banten, dengan waktu pelaksanaan yaitu bulan Agustus 2018 s/d Oktober 2018.

\subsection{Populasi dan Sampel}

Populasi ialah kumpulan yang lengkap dari elemen-elemen yang sejenis akan tetapi dapat dibedakan karena karakteristiknya (Supranto, 2017).Target yang akan menjadi populasi dalam penelitian ini adalah pelaku usaha perdagangan online, pembeli online baik dari media sosial maupun konsumen marketplace dan masyarakat umum yang menggunakan jasa perusahaan pengiriman.

Sampel atau contoh ialah sebagian dari populasi, elemen-elemen anggota sampel merupakan anggota populasi dari mana sampel diambil (Supranto, 2017). Pada penelitian ini sampel yang digunakan sebanyak 100 responden dengan menggunakan sampling purposive yaitu teknik penentuan sampel dengan pertimbangan atau kriteria-kriteria tertentu.

\subsection{Teknik Pengumpulan Data}

Teknik pengumpulan data yang digunakan dalam penelitian ini yaitu: Observasi (Pengamatan), Kuisioner, Wawancara dan Studi Pustaka

\subsection{Metode Pengolahan dan Analisis Data}

Data diolah dan dianilisis dengan menggunakan metode Analytical Hierarchy Process (AHP) dan metode Technique For Order Preference by Similarity to Ideal Solution (TOPSIS)

\section{HASIL DAN PEMBAHASAN}

Setelah dilakukan perhitungan dan analisa hasil dari kuisioner tahap I,ternyata terdapat 7 kriteria yang diajukan peneliti yaitu pelacakan online (PO), biaya kirim (BK), ganti rugi kehilangan (GR), jangkauan area (JA), waktu pengiriman (WP), keamanan kiriman(KK) dan pilihan layanan (PL). setelah dilakukan perhitungan didapatkan kriteria yang dipilih oleh pengguna jasa pemilihan perusahaan jasa pengiriman adalah kriteria pelacakan online sebesar 10,08\%, biaya kirim sebesar $18,84 \%$, ganti rugi sebesar 9,83\%, jangkauan area sebesar $15,04 \%$, waktu pengiriman sebesar $18,38 \%$, keamanan kiriman sebesar 16,89\% dan pilihan layanan sebesar 10,94\%. 


\section{STATMAT}

(Jurnal Statistika dan Matematika)
P-ISSN: 2655-3724

STATMAT (Jurnal Statistika dan Matematika), Vol. 1, No. 1, Januari 2019 Halaman : 78-87

@ Prodi S-1 Matematika FMIPA Unpam

\subsection{Perhitungan Pembobotan Alternatif Untuk Setiap Kriteria}

Perhitungan ini dilakukan untuk mengetahui tingkat prioritas alternatif pada setiap kriteria dalam pemilihan perusahaan jasa pengiriman.

Berdasarkan perhitungan, diperoleh data, Pertama: Perhitungan pembobotan alternatif untuk kriteria pelacakan online dalam pemilihan perusahaan pengiriman, yaitu Pos Indonesia sebesar 28,61\%, TIKI sebesar 35,01\% dan JNE sebesar 36,38\%. Kedua Perhitungan Pembobotan Alternatif Untuk Kriteria Biaya Kirim berdasarkan perhitungan diperoleh nilai prioritas untuk setiap alternatif pada kriteria pelacakan online dalam pemilihan perusahaan pengiriman, yaitu Pos Indonesia sebesar 33,64\%, TIKI sebesar 33,31\% dan JNE sebesar 33,05\%. Ketiga Perhitungan Pembobotan Alternatif Untuk Kriteria Ganti Rugi berdasarkan perhitungan diperoleh urutan prioritas lokal untuk kriteria Ganti Rugi yaitu JNE menjadi prioritas pertama dengan nilai bobot 0,3759 atau 37,59\%, kemudian TIKI menjadi prioritas ke-2 dengan nilai bobot 0,3723 atau 37,23\%, Pos Indonesia menjadi prioritas ke-3 dengan nilai 0,2517 atau 25,17\%. Keempat Pembobotan Alternatif Untuk Kriteria Jangkauan Area berdasarkan perhitungan diperoleh urutan prioritas lokal untuk kriteria Jangkauan Area yaitu Pos Indonesia menjadi prioritas pertama dengan nilai bobot 0,3670 atau 36,7\%, kemudian JNE menjadi prioritas ke-2 dengan nilai bobot 0,3461 atau 34,61\%, TIKI menjadi prioritas ke-3 dengan nilai 0,2869 atau 28,69\%. Kelima Perhitungan Pembobotan Alternatif Untuk Kriteria Waktu Pengiriman, berdasarkan perhitungan diperoleh urutan prioritas lokal untuk kriteria Waktu Pengiriman yaitu JNE menjadi prioritas pertama dengan nilai bobot 0,3628 atau $36,28 \%$, kemudian TIKI menjadi prioritas ke-2 dengan nilai bobot 0,3455 atau 34,55\%, Pos Indonesia menjadi prioritas ke-3 dengan nilai 0,2916 atau 29,16\%. Ketujuh Perhitungan Pembobotan Alternatif Untuk Kriteria Keamanan Kiriman, berdasarkan perhitungan diperoleh urutan prioritas lokal untuk kriteria Keamanan Kiriman yaitu TIKI menjadi prioritas pertama dengan nilai bobot 0,3652 atau 36,52\%, kemudian Pos Indonesia menjadi prioritas ke-2 dengan nilai bobot 0,3333 atau 33,33\%, JNE menjadi prioritas ke-3 dengan nilai 0,3015 atau 30,15\%. Kedelapan Perhitungan Pembobotan Alternatif Untuk Kriteria Pilihan Layanan, berdasarkan perhitungan diperoleh urutan prioritas lokal untuk kriteria Pilihan Layanan yaitu Pos Indonesia menjadi prioritas pertama dengan nilai bobot 0,3375 atau $33,75 \%$, kemudian TIKI menjadi prioritas ke-2 dengan nilai bobot 0,3370 atau $33,70 \%$, JNE menjadi prioritas ke-3 dengan nilai 0,3255 atau $32,55 \%$. Jadi referensi konsumen mengenai bobot prioritas kriteria dalam pemilihan perusahaan jasa pengiriman yang dianalisa dengan menggunakan metode AHP adalah kriteria biaya kirim yang menjadi prioritas utama dengan bobot prioritas sebesar 0,1884 , diikuti dengan kriteria waktu pengiriman 0,1838, keamanan kiriman 0,1689, jangkauan area 0,1504, pilihan layanan 0,1094, pelacakan online 0,1008 dan ganti rugi 0,9830 . 
(Jurnal Statistika dan Matematika)

\subsection{Penyusunan Matriks Keputusan}

Setelah dilakukan perhitungan pada setiap kriteria dan alternatf dan diperoleh tingkat prioritas dari setiap kriteria dan alternative pada masing-masing kriteria dalam pemilihan perusahaan jasa pengiriman, maka dapat dilakukan penyusunan matriks keputusan.

Matriks keputusan disusun dengan cara memasukkan semua vector eigen atan nilai prioritas yang telah dihitung kedalam sebuah matriks yang sesuai dengan selnya sehingga diperoleh hasil berikut ini :

Tabel 1 Matriks Keputusan

\begin{tabular}{cccccccc}
\hline \multirow{2}{*}{ PERUSAHAAN } & \multicolumn{7}{c}{ Kriteria } \\
\cline { 2 - 8 } & PO & BK & GR & JA & WP & KK & PL \\
\hline POS INDONESIA & 0,2861 & 0,3364 & 0,2517 & 0,3670 & 0,2916 & 0,3333 & 0,3375 \\
TIKI & 0,3501 & 0,3331 & 0.3723 & 0,2869 & 0,3455 & 0,3652 & 0,3370 \\
JNE & 0,3638 & 0,3305 & 0,3759 & 0,3461 & 0,3628 & 0,3015 & 0,3255 \\
\hline
\end{tabular}

\subsection{Perhitungan Matriks Keputusan Ternormalisasi}

Matriks keputusan yang telah disusun kemudian dinormalisasikan agar masing-masing vektor dari setiap kriteria memiliki panjang yang sama. Matriks keputusan dinormalisasikan dengan rumus sebagai berikut:

$$
r_{i j}=\frac{x_{i j}}{\sqrt{\sum_{i}^{m} x_{i j}^{2}}}, i=1,2,3, \ldots, m ; j=1,2,3 \ldots, m
$$

Tabel 2 Matriks Keputusan

\begin{tabular}{cccccccc}
\hline \multirow{2}{*}{ PERUSAHAAN } & \multicolumn{7}{c}{ KRITERIA } \\
\cline { 2 - 8 } & PO & BK & GR & JA & WP & KK & PL \\
\hline POS INDONESIA & 0,2861 & 0,3364 & 0,2517 & 0,3670 & 0,2916 & 0,3333 & 0,3375 \\
TIKI & 0,3501 & 0,3331 & 0.3723 & 0,2869 & 0,3455 & 0,3652 & 0,3370 \\
JNE & 0,3638 & 0,3305 & 0,3759 & 0,3461 & 0,3628 & 0,3015 & 0,3255 \\
\hline
\end{tabular}

$$
\left|x_{1}\right|=\sqrt{0,2861^{2}+0,3501^{2}+0,3638^{2}}=0,5803
$$


(Jurnal Statistika dan Matematika)

$$
\begin{aligned}
& r_{11}=\frac{x_{11}}{\left|x_{1}\right|}=\frac{0,2861}{0,5803}=0,4930 \\
& r_{21}=\frac{x_{21}}{\left|x_{1}\right|}=\frac{0,3501}{0,5803}=0,6033 \\
& r_{31}=\frac{x_{31}}{\left|x_{1}\right|}=\frac{0,3638}{0,5803}=0,6269
\end{aligned}
$$

Dengan cara yang saya didapat hasil perhitungan seperti pada Tabel 3 berikut :

Tabel 3 Matriks Keputusan Ternormalisasi

\begin{tabular}{cccccccc}
\hline \multirow{2}{*}{ PERUSAHAAN } & \multicolumn{7}{c}{ Kriteria } \\
\cline { 2 - 8 } & PO & BK & GR & JA & WP & KK & PL \\
\hline POS INDONESIA & 0,4930 & 0,5826 & 0,4296 & 0,6324 & 0,5030 & 0,5755 & 0,5845 \\
TIKI & 0,6033 & 0,5769 & 0.6354 & 0,4944 & 0,5960 & 0,6306 & 0,5836 \\
JNE & 0,6269 & 0,5724 & 0,6416 & 0,5964 & 0,6259 & 0,5206 & 0,5637 \\
\hline
\end{tabular}

\subsection{Perhitungan Matriks Keputusan Ternormalisasi Terbobot}

Setelah didapatkan matriks keputusan ternormalisasi, maka langkah selanjutnya adalah menyusun matriks keputusan ternormalisasi terbobot. Matriks ternormalisasi yang terbobot ini dapat diperoleh dengan melakukan perhitungan yaitu mengalikan setiap kolom elemen matriks keputusan ternormalisasi dengan bobot prioritas setiap kriteria yang telah diperoleh pada perhitungan

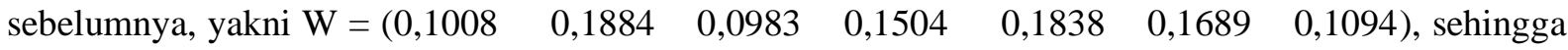
didapatkan dilakukan perhitungan sebagai berikut :

Tabel 4 Matriks Keputusan Ternormalisasi

\begin{tabular}{cccccccc}
\hline \multirow{2}{*}{ PERUSAHAAN } & \multicolumn{7}{c}{ Kriteria } \\
\cline { 2 - 8 } & PO & BK & GR & JA & WP & KK & PL \\
\hline POS INDONESIA & 0,4930 & 0,5826 & 0,4296 & 0,6324 & 0,5030 & 0,5755 & 0,5845 \\
TIKI & 0,6033 & 0,5769 & 0.6354 & 0,4944 & 0,5960 & 0,6306 & 0,5836 \\
JNE & 0,6269 & 0,5724 & 0,6416 & 0,5964 & 0,6259 & 0,5206 & 0,5637 \\
\hline$y_{11}=$ & $w_{1} r_{11}=(0,1008)(0,4930)=0,0497$
\end{tabular}

Dengan cara yang sama, didapatkan hasil perhitungan seperti pada Tabel 5 berikut :

Tabel 5 Matriks Keputusan Ternormalisasi Terbobot

\begin{tabular}{cccccccc}
\hline \multirow{2}{*}{ PERUSAHAAN } & \multicolumn{7}{c}{ Kriteria } \\
\cline { 2 - 8 } & PO & BK & GR & JA & WP & KK & PL \\
\hline POS INDONESIA & 0,0497 & 0,1098 & 0,0422 & 0,0951 & 0,0925 & 0,0972 & 0,0639 \\
TIKI & 0,0608 & 0,1087 & 0,0625 & 0,0744 & 0,1095 & 0,1065 & 0,0638 \\
JNE & 0,0632 & 0,1078 & 0,0631 & 0,0897 & 0,1150 & 0,0879 & 0,0617 \\
\hline
\end{tabular}


(Jurnal Statistika dan Matematika)

\subsection{Menentukan Solusi Ideal Positif dan Solusi Ideal Negatif}

Solusi Ideal Positif (SIP) dapat diperoleh dengan cara mencari nilai terbesar atau nilai maksimum dari semua alternatif terhadap setiap kriteria pada matriks keputusan ternormalisasi terbobot jika kriteria tersebut merupakan kriteria keuntungan.

Sebaliknya, Soluai Ideal Positif (SIP) dapat diperoleh dengan cara mencari nilai terkecil dari semua alternatif terhadap setiap kriteria pada matriks keputusan ternormalisasi terbobot jika kriteria tersebut merupakan kriteria biaya.

Karena kriteria yang telah ditetapkan merupakan kriteria keuntungan maka yang akan dicari adalah nilai terbesar atau maksimum dari semua altenatif terhadap masing-masing kriteria sehingga diperoleh solusi ideal positif sebagai berikut :

Tabel 6 Solusi Ideal Positif

\begin{tabular}{cccccccc}
\hline Kriteria & PO & BK & GR & JA & WP & KK & PL \\
\hline Nilai Maksimum $\left(\mathbf{A}^{+}\right)$ & 0,0632 & 0,1098 & 0,0631 & 0,0951 & 0,1150 & 0,1065 & 0,0639 \\
\hline
\end{tabular}

Tabel 7 Solusi Ideal Negatif

\begin{tabular}{cccccccc}
\hline Kriteria & PO & BK & GR & JA & WP & KK & PL \\
\hline Nilai Minimum $\left(A^{-}\right)$ & 0,0497 & 0,1078 & 0,0422 & 0,0744 & 0,0925 & 0,0879 & 0,0617 \\
\hline
\end{tabular}

\subsection{Menghitung Separasi}

Setelah didapatkan Solusi Ideal Positif maka dapat dilakukan perhitungan separasi dari setiap alternatif untuk memperoleh jarak pendekatan dari setiap alternatif terhadap Solusi Ideal Positif. Separasi terhadap Solusi Ideal Positif diperoleh dengan menggunakan rumus: $S_{i}^{+}=\sqrt{\sum_{j=1}^{n}\left(y_{i j}-y_{j}^{+}\right)^{2}}, i=1,2,3, \ldots, \mathrm{n}$. Dengan menggunakan formula tersebut, didapat hasil seperti tabel berikut :

Tabel 8 Hasil Perhitungan Separasi Solusi Ideal Positif

\begin{tabular}{cc}
\hline Perusahaan & Jarak Terhadap Solusi Ideal Positif \\
\hline Pos Indonesia & 0,0348 \\
TIKI & 0,0216 \\
JNE & 0,0196 \\
\hline
\end{tabular}


(Jurnal Statistika dan Matematika)
P-ISSN: 2655-3724

STATMAT (Jurnal Statistika dan Matematika), Vol. 1, No. 1, Januari 2019 Halaman : 78-87

@Prodi S-1 Matematika FMIPA Unpam

Dari Tabel 8 dapat disimpulakan bahwa JNE memiliki jarak terdekat dengan solusi ideal positif dalam pemilihan jasa perusahaan pengiriman yaitu sebesar 0,0196, diikuti oleh TIKI sebesar 0,0216 dan yang terjauh adalah Pos Indonesia yakni sebesar 0,0348.

\subsection{Perhitungan Nilai Preferensi dan Menentukan Perusahaan Jasa Pengiriman Terbaik.}

Menghitung nilai preferensi atau jarak kedekatan relatif dilakukan dengan cara membagi setiap jarak alternatif terhadap solusi ideal negatif dengan jumlah jarak alternatif terhadap solusi ideal positif dan jarak alternatif terhadap solusi ideal negatif. Sedemikian sehingga diperoleh sebagai berikut:

$$
\begin{aligned}
& C_{1}=\frac{0,0229}{0,0348+0,0229}=0,3969 \\
& C_{2}=\frac{0,0343}{0,0216+0,0343}=0,6136 \\
& C_{3}=\frac{0,0369}{0,0196+0,0369}=0,6531
\end{aligned}
$$

Tabel 9 Nilai Preferensi

\begin{tabular}{cc}
\hline Perusahaan & Nilai Preferensi \\
\hline Pos Indonesia & 0,3969 \\
TIKI & 0,6136 \\
JNE & 0,6531 \\
\hline
\end{tabular}

Jadi, preferensi konsumen dalam pemilihan perusahaan jasa pengiriman terbaik yang dianalisa dengan menggunakan metode TOPSIS menunjukkan bahwa JNE memiliki nilai terbesar, yaitu sebesar 0,6513, diikuti oleh TIKI dengan nilai 0,6136 dan Pos Indonesia dengan nilai sebesar 0,3969. Dengan demikian, JNE merupakan solusi terbaik dalam pemilihan perusahaan jasa pengiriman.

\section{KESIMPULAN DAN SARAN}

\subsection{Kesimpulan}

Berdasarkan hasil perhitungan yang telah dilakukan pada bab sebelumnya dapat disimpulkan bahwa:

4.1.1. Preferensi konsumen mengenai bobot prioritas kriteria dalam pemilihan perusahaan jasa pengiririman terbaik yang dianalisa dengan menggunakan metode AHP menunjukkan bahwa kriteria yang memiliki bobot prioritas terbesar secara berurutan adalah kriteria biaya kirim, waktu pengiriman, keamanan kiriman, jangkauan area, pilihan layanan, pelacakan online dan ganti rugi. Sedangkan preferensi konsumen mengenai bobot prioritas alternatif pada setiap kriteria adalah sebagai berikut: 
(Jurnal Statistika dan Matematika)
P-ISSN: 2655-3724

STATMAT (Jurnal Statistika dan Matematika), Vol. 1, No. 1, Januari 2019 Halaman : 78-87

@Prodi S-1 Matematika FMIPA Unpam

a. Pada kriteria pelacakan online, bobot prioritas alternatif terbesar secara berurutan dimiliki oleh JNE, TIKI, Pos Indonesia.

b. Pada kriteria biaya kirim, bobot prioritas alternatif terbesar secara berurutan dimiliki oleh Pos Indonesia, TIKI, JNE

c. Pada kriteria ganti rugi, bobot prioritas alternatif terbesar secara berurutan dimiliki oleh JNE, TIKI, Pos Indonesia

d. Pada kriteria jangkauan area, bobot prioritas alternatif terbesar secara berurutan dimiliki oleh Pos Indonesia, JNE, TIKI

e. Pada kriteria waktu pengiriman, bobot prioritas alternatif terbesar secara berurutan dimiliki oleh JNE, TIKI, Pos Indonesia

f. Pada kriteria keamanan kiriman, bobot prioritas alternatif terbesar secara berurutan dimiliki oleh TIKI, Pos Indonesia, JNE

g. Pada kriteria pilihan layanan, bobot prioritas alternatif terbesar secara berurutan dimiliki oleh Pos Indonesia, TIKI, JNE

4.1.2. Preferensi konsumen dalam pemilihan perusahaan jasa pengiriman terbaik yang dianalisa dengan menggunakan metode TOPSIS menunjukkan bahwa JNE memiliki nilai preferensi terbesar, diikuti oleh TIKI kemudian Pos Indonesia. Dengan demikian, JNE merupakan solusi terbaik dalam pemilihan perusahaan jasa pengiriman.

\subsection{Saran}

Berdasarkan hasil analisa dan kesimpulan yang diperoleh, peneliti memberikan saran diantaranya:

\subsubsection{Bagi Perusahaan Jasa Pengiriman}

a. Perusahaan harus terus memperbaiki pelayanan terhadap konsumen demi mendapat loyalitas dan kepuasan dari konsumen.

b. Mengingat bahwa kriteria yang menjadi prioritas utama adalah biaya kirim, maka sudah seharusnya perusahaan jasa pengiriman lebih bersaing dalam menentukan tarif biaya kirim tanpa mengurangi kualitas pelayanan.

4.2.2. Pada penelitian selanjutnya diharapkan mahasiswa mampu melakukan penelitian lebih mendalam tidak hanya kriteria, tapi sampai ke sub kriteria dan bisa membuat aplikasi Sistem Pendukung Keputusan (SPK) untuk metode AHP dan TOPSIS ini agar mempercepat dalam pengambilan keputusan

\section{REFERENSI}

Pritiwi, Heny. 2017. Buku ajar sistem pendukung keputusan. Yogyakarta: Deepublish

Sari, Febrina. 2017. Metode dalam mengambil keputusan. Yogyakarta: Deepublish 
(Jurnal Statistika dan Matematika)

Supranto, J,M,A. Teknik sampling untuk survery dan penelitian. Jakarta: Rineka Cipta

Yoon, K dan L, Hwang,. 1980. TOPSIS (Technique For Order Preference by Similarity to Ideal Solution) - A multiple Attribute Decision Making. A paper to be Published 